\title{
HOBBES Y SPINOZA FRENTE A LOS DESAFÍOS \\ DE LA MODERNIDAD
}

LUIS SALAzAR C.

DePaRTAMENTO DE FLLOSOFIA

UNIVERSIDAD AUTÓNOMA METROPOLITANA-AZCAPOTZALCO

\section{Introducción}

En los tiempos que corren es frecuente oír hablar, dentro de los ámbitos filosóficos, de una crisis, un agotamiento o incluso un final de la modernidad. Con diversos tonos, matices y perspectivas, parece existir la sensación generalizada de que el término del siglo XX y del segundo milenio de nuestra era ha implicado el término de un época histórica, y con ella, de cierta manera de hacer y entender la filosofía. Así se afirma, por ejemplo, que el derrumbe del llamado "socialismo real", lo mismo que las catástrofes generadas por el fascismo y por las dos guerras mundiales, suponen "el fracaso del proyecto ilustrado". ${ }^{1}$ Otros, con no menos fuerza, avanzan la tesis de que hemos vivido "tras la virtud", 2 esto es, una época del pensamiento filosófico que falló en su intento de fundar racionalmente los valores morales y políticos $y$, por ende, condujo no sólo a esas tragedias, sino a un nihilismo generalizado que requiere reconsiderar y rechazar las bases mismas de la filosofía moderna.

No se trata aquí de tomar posición frente a tales diagnósticos y posturas, que en todo caso parecen suponer demasiados compromisos teóricos y prácticos. Sólo interesa, en cambio, verlos como el síntoma de que, en efecto, las experiencias de nuestro siglo parecen exigir una revisión a fondo de nuestra manera de comprender y de ejercer la reflexión filosófica, y de entender las bases mismas de lo que llamamos "modernidad". Si, por diversas razones, parece por lo menos prematuro celebrar los funerales de la cultura moderna; si, de la misma manera, resulta poco prudente asumir que hemos pasado a lo que algunos denominan "posmodernidad", en cambio sí parece indispensable tomar nota de que ciertas tradiciones y formas filosóficas -desarrolladas a partir de Descartes- hoy se muestran no só-

1 Postura muy socorrida por el Vaticano. Véase por ejemplo Juan Pablo II, Cruzando el umbral de la esperanza, Plaza \& Janés, México, 1994.

2 Cfr. A. MacIntyre, Tras la virtud, Editorial Crítica, Barcelona, 1987. 
lo cuestionadas sino incluso imposibilitadas por las duras lecciones de la propia historia moderna.

Pero esta necesaria reconsideración de la filosofía moderna - si ha de ser algo más que expresión de nuestros estados de ánimo actuales- ha de ser algo mucho más serio, detallado y preciso que un Gran Rechazo o una Gran Apología globales y rotundos. Ha de ser una reflexión serena y objetiva de lo que los grandes clásicos de dicha filosofía han aportado en cuanto cuestiones, argumentaciones, esclarecimientos y compromisos racionales, a la vez que un reconocimiento de la inevitable distancia - histórica y cultural- que nos separa de ellos. ${ }^{3}$ Se trata entonces de verlos justamente como autores "clásicos" por cuanto al menos algunas de sus tesis, de sus formulaciones, de sus preocupaciones y hasta de sus errores, siguen configurando puntos de referencia obligados para nuestras reflexiones actuales. Es dudoso que sus propuestas nos puedan parecer totalmente adecuadas; es por el contrario de esperarse que su manera de hacer filosofía nos parezca extraña e incluso exótica. Pero su naturaleza de "clásicos" de la filosofía reside en que, pese a todo, sus obras nos siguen diciendo algo importante, algo que nos obliga a pensar, a reflexionar y a cuestionar nuestras propias posiciones e ideas.

Bajo estas premisas, una manera sugerente de abordar a los grandes filosofos del siglo XVII es preguntarnos cuáles eran sus preocupaciones básicas -qué querían hacer con su filosofía- y cómo, partiendo de ellas, pretendían afrontar lo que hemos llamado "los desafíos de la modernidad". Tal itinerario, que en manera alguna intenta ser exhaustivo, acaso posibilite una introducción atractiva a la inmensa complejidad de sus sistemas filosóficos, permitiendo entender a la vez su peculiaridad y su inserción en una época determinada, así como las lecciones y cuestiones que podemos sacar de su experiencia filosófica. Al mismo tiempo, podremos observar que, contra lo que afirma un mito recurrente de la historia de la filosofía moderna, ésta estuvo lejos de ser el desarrollo simple y lineal de las posiciones avanzadas por Descartes, al que si bien es posible considerar uno de los grandes iniciadores de esta historia, no es en cambio razonable considerar el origen único y ni siquiera predominante de sus temas y cuestiones centrales.

Pero vayamos por orden y preguntémonos cuáles son, esquemáticamente presentados, estos grandes desafíos de la modernidad.

3 Interesante desde este punto de vista es el libro de A. Touraine, Crítica de la modernidad, Fondo de Cultura Económica, México, 1995. También cfr. L. Villoro, "Filosofía para un fin de época", en N. Rabotnikof y C. Yturbe, La tenacidad de la política, UNAM, IIF, México, 1995. 


\section{La síntesis teológico-política y su disolución histórica}

Como es sabido, el tránsito de la Edad Media a la Edad Moderna fue promovido por el Renacimiento, la Reforma Protestante, la formación de los primeros Estados Nacionales en Europa y, a nivel del pensamiento teórico, por los grandes descubrimientos científicos y geográficos que pusieron fin - progresivamente- a la cosmovisión escolástica del mundo. Aunque generados por causas heterogéneas - culturales, religiosas, políticas y propiamente intelectuales - todos estos desarrollos pusieron en crisis y posibilitaron la superación de la gran síntesis teológico-política codificada por Santo Tomás y los escolásticos, es decir, el núcleo teórico e intelectual de una cosmovisión que hasta entonces había sido hegemónica, aunque no sin tensiones ni conflictos.

Así, el Renacimiento supuso no sólo una increíble explosión de creatividad artística e intelectual, sino que implicó una primera ruptura liberadora con respecto del pensamiento propiamente religioso y teológico. Se trataba de recuperar, de un modo o de otro, la tradición del pensamiento clásico griego y latino, más acá y más allá de su interpretación teológica, poniendo por así decirlo las bases de un nuevo pensamiento laico, racionalista e independiente de presupuestos biblicos o dogmáticos. Las obras artísticas y filosóficas de los autores renacentistas -incluso cuando se inspiraban en temas de la religión católica- suponían en este sentido una nueva actitud frente al mundo y frente al ser humano. Hoy todavía, al leer a Maquiavelo, a Pico della Mirandola, a Leonardo y a Bruno, podemos percibir esa modificación radical que hacía de lo terrenal, de lo mundano, de la llamada luz natural de la razón, los principios predominantes para el ejercicio del arte, de la política, de la técnica y de la ciencia. Surgía así, en medio de conflictos y tensiones dramáticas, un nuevo humanismo que, bajo el ejemplo de las civilizaciones de la Atenas democrática y de la Roma republicana, desplazaba las cuestiones propias de una visión teocéntrica del universo en beneficio de una cosmovisión diferente, abierta, crítica, racionalista.

Un impulso civilizatorio muy diverso surgiría con la Reforma Protestante. Afrontando lo que les parecía una inmensa corrupción y profanación de la fe cristiana, los reformadores como Lutero y Calvino también intentarían un retorno al pasado, pero en este caso al pasado prístino y primigenio del cristianismo, a la verdadera fe expresada en los Evangelios, más allá y más acá de su institucionalización y terrenalización eclesiástica y católica. Como en el caso del Renacimiento, y acaso de modo todavía más paradójico, estos esfuerzos sin embargo conducirían a una verdadera revolución espiritual que, contra las intenciones estrictamente religiosas de sus promotores, generaría no sólo las bases culturales de un nuevo individualismo, de una nueva manera de entender la moral y la política, sino incluso buena parte 
de las condiciones favorables para el surgimiento y la consolidación de los Estados Nacionales.

Las guerras de religión desencadenadas por la Reforma, en efecto, volverían progresivamente indispensable la emergencia -en parte también restauración - de una nueva concepción (laica) de la política y de lo político, así como el surgimiento de esa gran invención de la política moderna que son los Estados Nacionales. En tal desarrollo intervinieron sin duda factores de la más diversa índole -demográficos, territoriales, económicos y culturales - pero parece indiscutible que el desplome de la unidad católica del cristianismo, de la hegemonía indiscutida del Vaticano, generó turbulencias y conflictos que sólo pudieron afrontarse configurando un nuevo tipo de poder político, un nuevo tipo de instancia capaz de imponer una nueva forma de unificación y pacificación a la convivencia social.

Junto con estos enormes cambios culturales e institucionales, que habrían de demoler las bases mismas de la civilización medieval, es necesario considerar, además, la irrupción de la nueva ciencia, la de Copérnico, Kepler y Galileo que, por así decirlo, se encargaría de dar la puntilla a las cosmovisión escolástica y aristotélica hasta entonces dominante. Del cosmos cerrado, jerárquicamente ordenado y teleológicamente orientado donde la tierra ocupaba un lugar central y donde las esferas supralunares aparecian como el lugar de la eternidad, la humanidad pasaría a vivir en un universo abierto, infinito, sin fines y sin límites, en todo caso comprensible mediante leyes causales universales, pero carente de todo sentido axiológico o teleológico. Esta nueva concepción del mundo provocaría una verdadera revolución intelectual que sería saludada por unos - como Bruno- con entusiasmo, y por otros - como Pascal - con temor, pero de cualquier manera conduciría inevitablemente a un cuestionamiento radical de todos los temas filosóficos.

Esta nueva concepción de la naturaleza, en efecto, no sólo implicaba rechazar las imágenes teocéntricas y geocéntricas hasta entonces dominantes; no sólo suponía un rechazo de la física y de buena parte de la ontología aristotélica y de sentido común, también conllevaba un nuevo modelo de racionalidad, una nueva manera de comprender y explicar, un nuevo ideal epistémico que, paulatinamente, habría de convertirse en dominante. No es, por ende, casual que su irrupción revolucionaria haya dado lugar a una verdadera crisis cultural y, sobre todo, a un enorme conflicto con los poderes teológicos, religiosos y políticos dominantes. Los portadores de esta nueva forma de conocimiento, en efecto, sólo podrían verse con sospecha, con temor e incluso con odio por parte de todos aquellos que veían cuestionados los dogmas y los mitos que sustentaban su autoridad, sus privilegios, su dominación teológico-política. Tanto la Iglesia Católica como las iglesias 
reformadas por ello combatirían ferozmente la nueva ciencia y la nueva filosofía como atentados libertinos y ateos que socavaban las bases mismas de la fe, de las instituciones de dominación y del papel central de la religión en la vida política y social.

Por ello, al leer autores como Descartes, como Hobbes y como Spinoza, debemos tener presente que sus obras -que inauguraban de hecho una nueva época para el pensamiento racional- se elaboraron en un ambiente que hacía de la reflexión crítica un compromiso riesgoso e irritante, capaz de desencadenar las furias y el odio más temibles, así como verdaderas campañas persecutorias contra sus protagonistas. La separación de la filosofía con relación a la teología y la religión, y su ejercicio libre de presupuestos dogmáticos estuvo muy lejos de ser un proceso pacífico. Tanto Descartes, como Hobbes y Spinoza habrían de sufrir los ataques, calumnias y condenas de los poderes eclesiásticos y/o teológico-políticos que los consideraban enemigos no sólo del orden social existente, sino de sus baluartes ideológicos y ontológicos. ${ }^{4}$

No es casual, en este contexto, la cautela mostrada por Descartes que, afirmando la necesidad de refundar radicalmente el saber sobre bases y certezas ajenas a la tradición y a los prejuicios, formulaba al mismo tiempo la necesidad de establecer una moral provisional que no cuestionara los usos y costumbres establecidos. Como no es casual que intentara convencer a sus lectores de que su filosofía no sólo no iba contra los dogmas básicos de la fe cristiana, sino que, en los hechos, le daba un fundamento racional e indiscutible. A fin de cuentas todo el sistema filosófico cartesiano puede considerarse un gran esfuerzo por reconciliar y armonizar los nuevos ideales epistemológicos, la nueva forma del saber científico, con la moral y la teología tradicionales. Y no obstante, teólogos católicos y protestantes denunciarían a la filosofía de Descartes como ateísmo y libertinaje, como un pensamiento peligroso por ende para la verdadera fe y la verdadera moralidad. Y el mismo tipo de condenas, incluso agravadas, recibirían las filosofías de Hobbes y de Spinoza, al extremo de que, por mucho tiempo, las obras de estos dos autores enfrentarían la censura por parte de todos los poderes eclesiásticos y hasta civiles.

Cabe pues preguntarnos cuáles eran las razones de la irritación inmensa provocada por obras filosóficas que, en la práctica, no sólo eran inaccesibles para la gran mayoría de sus contemporáneos, sino que difícilmente planteaban algo políticamente subversivo. ¿Por qué, a pesar de la cautela de sus autores, a pesar de ser escritas por sabios que simplemente defen-

4 Sobre la atmósfera intelectual del siglo XVII, cfr. la segunda parte de E.L. Baumer, $E l$ pensamiento europeo moderno. Continuidad y cambio en las ideas, 1600/1950, Fondo de Cultura Económica, México, 1985. 
dían una nueva manera de filosofar, parecían tan peligrosas, tan temibles, tan problemáticas e irritantes? Como intentaremos ver, lo parecían porque efectivamente anunciaban y sentaban las bases de un racionalismo que, no sin tensiones y dificultades, suponía una nueva manera, laica y secular, de abordar y enfrentar las cuestiones centrales de la moral y de la política. Una nueva manera - propiamente modierna - de entender el mundo social, sus bases y sus posibilidades.

Para comprender lo anterior baste señalar esquemáticamente que para la visión teocéntrica, teológica, hasta entonces dominante, la existencia y la naturaleza de Dios - revelada por los textos sagrados, y reafirmada por las pruebas "racionales" de la luz natural- eran la base o fundamento tanto de la autoridad política - pues, como decía San Pablo, todo poder viene de Dios-, como de las normas y valores morales —entendidos como mandamientos, es decir, como leyes dictadas por Dios a través de sus profetas, Mesías y apóstoles. De ahí que el primer desafío de la modernidad tuviera que ver precisamente con estas cuestiones, es decir, con la de la presunta existencia de un Dios todopoderoso, creador de cielo y tierra, y con la todavía más problemática cuestión de su naturaleza como Monarca universal.

Las nuevas concepciones acerca de la naturaleza y acerca del universo, en efecto, contradecían, para empezar, el presunto saber revelado en los Textos Sagrados. El nuevo rigor científico de carácter matemático y deductivo, no sólo volvía irrisorios los presupuestos de las viejas narraciones bíblicas, sino que obligaba a verlas como historias cargadas de sospechosos fenómenos sobrenaturales, propiamente incomprensibles desde el punto de vista racional. La supersticiosa creencia en los milagros, en las intervenciones arbitrarias de una voluntad divina sobrenatural, necesariamente chocaba con el nuevo ideal epistémico de una explicación de los fenómenos y procesos naturales a partir de leyes universales y causas próximas. Se abría, por así decirlo, un abismo entre los nuevos criterios de investigación y explicación de la naturaleza, y la mayor parte de los supuestos dogmáticos, milagrosos y míticos que impregnaban los relatos y tradiciones religiosos. Por ello, para salvar de alguna manera la cuestión, Descartes por un lado pretendía convertir la existencia de Dios en un postulado racional de su sistema, pero por otro reconocía que la naturaleza de esa sustancia divina era inaccesible para la razón, esto es, incomprensible desde el punto de vista racional. Pero poco importaban las intenciones del filósofo francés, su filosofía de hecho abriría el camino a un cuestionamiento cada vez más radical de la luz revelada, de las narraciones y tradiciones bíblicas, como un conjunto de leyendas e historias sustentadas tan sólo en la ignorancia, los prejuicios y las supersticiones de pueblos más bien bárbaros y primitivos. 
La segunda cuestión desafiante que habrian de afrontar nuestros filósofos era política. Hasta entonces, bajo el entendido de que la autoridad política venía de la voluntad divina, de un don arbitrario de Dios, legitimado por sus representantes eclesiásticos, la debida obediencia de los súbditos se fundaba fácilmente en términos teológicos. El Papa o sus representantes consagraban en vistosos ceremoniales de coronación a los monarcas, que a su vez debían defender la fe y la salvación de las almas de sus pueblos. La Reforma Protestante, sin embargo, haría imposible progresivamente dicha legitimación, al promover la existencia de diversas interpretaciones del cristianismo y de diversas corrientes sacerdotales, cada una de ellas convencida de poseer en exclusiva los bienes de salvación. Las guerras de religión, los combates teológico-políticos por defender con las armas las diferentes verdades dogmáticas en torno a la fe, hicieron cada vez más inviable la estabilización y legitimación religiosa del poder político. ¿Cómo saber, por ejemplo, si la iglesia luterana, o la iglesia calvinista, o la iglesia católica era la única capaz de hablar en nombre de un Dios que, por su parte, parecía hundido en el mayor de los silencios? ¿Cómo saber, en otras palabras, cuál era la voluntad de Dios si sus supuestos representantes se dividían y enfrentaban en relación con el sentido de la fe y la revelación?

Se hizo necesario, por ende, superar las justificaciones propiamente religiosas del poder político, o por decirlo de otra manera, separar las cuestiones de fe de las cuestiones políticas, estableciendo nuevas fuentes, propiamente laicas, para la legitimación y justificación de la autoridad terrenal. Ni el supuesto orden natural, ni la presunta razón o voluntad divinas, ni la mera tradición podían ya considerarse fundamento aceptable del orden político, que sólo podía verse, en adelante, como un orden construido por los propios seres humanos para fines estrictamente terrenales. La única manera de neutralizar los conflictos teológico-políticos era, precisamente, separar el problema de las bases del poder público, de los problemas relativos a las creencias religiosas. Los individuos, entonces, tendrían que aceptar o impugnar dicho poder ya no como fieles, ya no como católicos, calvinistas o luteranos, sino solamente como ciudadanos de una nación, esto es, como seres (virtualmente) racionales. La obediencia o la rebelión tendrían a su vez que justificarse ya no en mandamientos divinos, ya no en la fe religiosa en un poder trascendente, ya no en función de una salvación del alma, sino mediante razones seculares, capaces de apelar precisamente a la racionalidad, a la razón misma de dichos individuos. Tal fue la base cultural del éxito del iusnaturalismo moderno, inaugurado como veremos por Thomas Hobbes.

Vinculado con esta problemática, pero en realidad quizá más difícil de afrontar, se encuentra el desafío implicado en el nuevo estatuto de los valo- 
res, normas y juicios morales. Si algo parecía indiscutible en la cosmovisión medieval era el origen y el fundamento divinos de la moralidad. El Creador era considerado no sólo la fuente primigenia de los mandamientos y por ende de las normas morales, sino también la razón última de su indispensable observancia, dada su capacidad de juzgar y penalizar tanto acciones como intenciones. En buena medida, la salvación o perdición del alma era vista como consecuencia de dicha observancia, mientras que la validez de los valores siempre era retrotraída a la voluntad suprema del supremo legislador. De ahí que la fe, la creencia en un Creador omnipotente fuese considerada el bastión decisivo para el reconocimiento de la moralidad, y que, por consecuencia, el ateísmo se viera ligado inexorablemente al libertinaje, al desenfreno de las pasiones y, en definitiva, a la ceguera frente a cualquier valor. Se trataba, por ende, de una moral heterónoma, donde las reglas y los valores aparecían como órdenes, como mandatos irrevocables, como obligaciones impuestas por un Padre eterno, vigilante y siempre dispuesto a castigar las transgresiones como pecados de desobediencia.

Ciertamente existía en la tradición filosófica grecolatina otra concepción de la ética y de la moral: la tradición de las virtudes, sea en su versión homérica, sea en su versión platónica, sea en su versión aristotélica. Empero dos obstáculos se presentaban para que ella fuera simplemente recuperada por los pensadores del siglo XVII: por un lado, dichas virtudes, ya desde Maquiavelo, pese a su atractivo parecían demasiado excelsas para sociedades que el cristianismo y el mercantilismo habían corrompido profundamente. Siendo virtudes propiamente heroicas sustentadas en una idea de ciudadanía democrática o republicana, no sólo implicaban un ideal de participación y jerarquía que se había vuelto prácticamente imposible, sino también un modo no individualista - propiamente comunitario- de la vida colectiva, contrario en todo y por todo al cosmopolitismo y al igualitarismo promovido por la religión cristiana. Por otro, esas mismas virtudes e ideales grecolatinos presuponían una concepción de la naturaleza y de la naturaleza humana que la nueva ciencia sólo podía rechazar. A fin de cuentas, las éticas de Platón y de Aristóteles implicaban una metafísica y una epistemología aparentemente periclitadas, obsoletas, y debían ser desplazadas por una concepción distinta, moderna, científica y racional de los valores, normas y juicios morales.

En suma, la disolución de la síntesis teológico-política implicó tres grandes desafíos para los filósofos de la naciente modernidad: un desafío ontológico - icómo pensar la naturaleza (el universo) a partir de los nuevos descubrimientos científicos? Un desafío político - ¿ icómo pensar y justificar el poder político sin apelar a un origen sagrado del mismo? Y un desafío ético - icómo pensar el estatuto de los valores, normas y juicios morales, 
independientemente de una presunta voluntad trascendente? Tratemos de considerar brevemente la manera en que Hobbes y Spinoza afrontan dichos desafíos.

\section{Preocupaciones y proyectos básicos}

Aunque parten de fuentes y contextos muy parecidos, las filosofías de Hobbes y de Spinoza se distinguen radicalmente de los planteamientos fundacionales de René Descartes. Para este último, en efecto, la motivación central reside indiscutiblemente en la refutación del escepticismo gnoseológico a través de la duda metódica capaz de demostrar y garantizar un fundamento indubitable de nuestras ideas y, con ello, de establecer la verdadera base sólida de todos nuestros conocimientos adecuados, tanto formales como empíricos. Se trata por ende de una filosofía centrada en las cuestiones propiamente gnoseológicas, y el propio Descartes se cuida muy bien de precisar los límites de su argumentación, poniendo a salvo de la misma los temas morales y políticos de su tiempo. Sólo una vez establecido ese fundamento último en el cogito y en la necesaria existencia de un Dios fatalmente bueno, este pensador aborda - sustentado en su dualismo ontológico derivado de aquel problema gnoseológico- de una manera más bien sesgada las cuestiones morales en Las pasiones del alma y en su correspondencia con la reina de Suecia.

En cambio, Hobbes y Spinoza apenas dedican algún espacio en sus filosofías a la refutación estrictamente gnoseológica del escepticismo. Ambos parten sin duda de la existencia de hecho de una nueva ciencia, de una nueva manera de acceder al conocimiento adecuado y de un nuevo modelo de rigor racionalista, y en este sentido se oponen claramente a cualquier escepticismo. Empero, a diferencia de Descartes, no les interesa tanto fundamentar este nuevo modelo epistemológico, sino sacar de él conclusiones atingentes a lo que, siguiendo a Aristóteles, podemos denominar filosofía práctica, esto es, a la ética y a la política. Si los descubrimientos cientificos de Copérnico, de Galileo y de Kepler suponen una nueva manera de entender la naturaleza, totalmente diferente y contrapuesta a la física y a la metafísica aristotélica; si la nueva ciencia implica una ruptura radical con la cosmovisión y la ontología medievales, entonces es necesario revisar a fondo, con ojos renovados, no solamente las concepciones tradicionales acerca del mundo natural sino también las que conciernen al mundo humano, esto es, la religión, la política y la moral.

Por lo demás, dicha revisión no atiende sólo a la irrupción de este nuevo modelo de conocimiento riguroso. Como veremos, se trata más bien 
de buscar a partir de él nuevos modos de comprender al ser humano, sus pasiones y sus acciones, porque las viejas tradiciones e instituciones medievales se muestran totalmente incapaces de responder a lo que hemos llamado los desafíos de la modernidad. Podemos decir, incluso, que tanto Hobbes como Spinoza parecen compartir una concepción donde la nueva racionalidad científica y técnica juega un papel central, capaz de posibilitar un planteamiento y una solución radicalmente innovadores a las dificultades que desde siempre agobian a los seres humanos. Pero ello requiere justamente extender el dominio de la nueva racionalidad y abarcar ya no sólo la mecánica celeste y el movimiento de los cuerpos en el espacio, sino la naturaleza y el comportamiento de esa naturaleza específica que es la naturaleza humana.

Pero si nuestros dos autores comparten esta visión optimista acerca del conocimiento racional, así como del carácter no teleológico y geométrico que han de asumir las explicaciones y demostraciones, sus preocupaciones y sus perspectivas divergen en puntos esenciales. Mientras que es posible afirmar que para el autor del Leviatán la preocupación y la perspectiva son fundamentalmente políticas, para el judío holandés el interés y el punto de vista son ante todo éticos. Ello por supuesto no significa desconocer la importancia que ambos dan a las cuestiones propiamente metafísicas, gnoseológicas o psicológicas. Pero en todo caso una buena comprensión de sus sistemas filosóficos exige tener muy en cuenta el sentido global de los mismos, y por consecuencia, el punto de vista que preside su elaboración.

Así, en el primer capítulo de De corpore, Hobbes establece que sin duda alguna las ciencias y técnicas relativas a la naturaleza han posibilitado enormes beneficios para la humanidad, asumiendo así la tesis de Bacon según la cual el saber es poder. Pero hablando más particularmente de la ciencia política afirma lo siguiente:

Pero la, utilidad de la filosofía moral y civil ha de estimarse, no tanto por las comodidades que tenemos al conocer estas ciencias, sino por las calamidades que sufrimos por no conocerlas. Ahora, todas esas calamidades que podrían evitarse mediante la industria humana, surgen de la guerra, pero principalmente de la guerra civil; porque de ella proceden matanzas, soledad y la carencia de todas las cosas. Pero la causa de la guerra no es que los hombres la quieran tener; porque la voluntad no tiene por objeto sino lo bueno, $o$ al menos lo que parece bueno. Tampoco es porque los hombres desconozcan que los efectos de la guerra son malos; ¿pues quién hay que no piense que la pobreza y la pérdida de la vida son grandes males? La causa, por ende, de la guerra civil es que los hombres no conocen las causas de la guerra ni de la paz, habiendo muy pocos que han aprendido aquellos deberes que unen y contienen a los hombres 
en paz, es decir, que han aprendido suficientemente las reglas de la vida civil. Ahora bien, el conocimiento de dichas reglas es filosofía moral. ${ }^{\mathrm{s}}$

El propósito central de Hobbes queda muy claro: establecer una nueva filosofía política, propiamente científica y rigurosa, que permita evitar mediante la fuerza de sus razones apodícticas, la ignorancia que hasta ahora ha conducido a los seres humanos a ser víctimas de las calamidades de la guerra civil. No se trata, pues, de saber por saber, ni siquiera por satisfacer nuestra curiosidad: se trata de saber para poder, para acceder a una comprensión adecuada de las reglas necesarias para vivir en paz y para evitar la guerra.

Muy diferente es, en cambio, la perspectiva de Spinoza. Aunque concordando con Hobbes en la necesidad de una vida social pacifica, para él la filosofía no es ni puede ser el instrumento para alcanzarla. De hecho, con enorme realismo, Spinoza asume que la filosofía es cosa de unos pocos, que interesa y afecta solamente a los que denomina "doctos". Ello no significa sin duda que no tenga o no pueda tener un propósito, incluso un propósito excelso, el estudio de la filosofía; pero en todo caso dicho propósito no puede ser prioritariamente político sino ético. Así, en el Tratado de la reforma del entendimiento, obra inédita de carácter programático, afirma:

Después que la experiencia me había enseñado que todas las cosas que suceden con frecuencia en la vida ordinaria, son vanas y fútiles, como veía que todas aquellas que eran para mí causa y objeto de temor, no contenían en sí mismas ni bien ni mal alguno a no ser en cuanto que mi ánimo era afectado por ellas, me decidi, finalmente, a investigar si existía algo que fuera un bien verdadero y capaz de comunicarse, y de tal naturaleza que, por sí solo, rechazados todos los demás, afectara el ánimo; más aún, si existiría algo que, hallado y poseído, me hiciera gozar eternamente de una alegría continua y suprema.

Y más adelante, en esa misma obra, concluye:

Éste es, pues, el fin al que tiendo: adquirir tal naturaleza y procurar que muchos la adquieran conmigo; es decir, que a mi felicidad pertenece contribuir a que otros muchos entiendan lo mismo que yo, a fin de que su entendimiento y su deseo concuerden totalmente con mi entendimiento y con mi deseo. Para que eso sea efectivamente así, es necesario entender la Naturaleza lo suficiente como para conseguir aquella naturaleza (humana). Es necesario, además, formar una sociedad, tal como cabría desear, a fin de que el mayor número posible de individuos alcance dicha naturaleza con la máxima facilidad y seguridad. ${ }^{6}$

5 T. Hobbes, Elements of Philosophy, First Section, Concerning Body, en The English Works of Thomas Hobbes, vol. I, Scientia Verlag Aalen, Alemania, 1966, p. 9.

6 B. Spinoza, Tratado de la reforma del entendimiento, Alianza Editorial, Madrid, 1988, pp. 75-80. 
A partir de estos textos podemos hacer las siguientes observaciones. En primer lugar, que tanto Hobbes como Spinoza intentan utilizar el nuevo modelo epistémico en el campo de la filosofía moral y política. En segundo lugar, que pese a lo anterior, asumen un punto de vista diferente en lo que respecta al propósito central de su filosofía, siendo fundamentalmente político en el caso de Hobbes y ético en el caso de Spinoza. De esta manera, mientras que el primero nos ofrece una perspectiva política de las cuestiones morales -y por ello su obra no debe leerse como una reflexión estrictamente ética o deontológica-, el segundo en cambio nos propone una perspectiva ética de la política, esto es, un marco donde el orden político aparece evaluado desde el punto de vista de una búsqueda del bien verdadero y de la felicidad suprema, y por ello los textos políticos de Spinoza no son solamente políticos, sino componentes de un proyecto ético-filosófico.

Pero las diferencias no terminan aquí. Estamos de hecho frente a dos concepciones diversas, incluso incompatibles, sobre el papel mismo de la tarea filosófica, sobre el propósito y las consecuencias del conocimiento racional. Mientras para Hobbes la filosofía en tanto ciencia demostrativa tiene una función instrumental, por cuanto es el medio para acceder a una vida pacífica y segura, evitando la disolución y la guerra civil, para Spinoza el saber filosófico tiene un sentido inmanente ya que es expresión y desarrollo de la potencia humana por excelencia, es decir, del entendimiento racional. En otras palabras, el filósofo de Malmesbury interpreta la fórmula "saber es poder" en un sentido técnico o tecnológico: el saber sirve para lograr fines externos al saber mismo, sean éstos comodidades, o la paz. En cambio, Spinoza se mantiene dentro de la tradición clásica que ve en la filosofía no un conocimiento utilitario, un saber para alcanzar determinados fines exteriores, sino un forma de vida superior, un desarrollo de nuestras facultades (o de nuestra potencia), un modo de lograr la virtud o la excelencia, que si bien requiere de bienes externos, en manera alguna se agota en ellos.

Así, Hobbes considerará la vida humana una carrera perpetua en pos de los más diversos bienes, un movimiento incesante donde la satisfacción de un deseo llevará a la búsqueda de otros bienes y que sólo terminará con la muerte. La felicidad será por ende definida como un progreso incesante de los deseos de un objeto a otro "ya que la consecución del primero no es otra cosa sino un camino para realizar otro ulterior". ${ }^{7}$ De ahí que el autor del Leviatán hable de una inclinación general de la humanidad entera a luchar por el poder, entendido como capacidad justamente de lograr la satisfacción de los deseos, esto es, como capacidad instrumental, como dominio sobre la naturaleza y sobre los demás seres humanos. Esta ambición desaforada, esta manera de entender la vida como movimiento perpetuo y como competencia

7 T. Hobbes, Leviathan, ed. cit., vol. III, p. 85. 
inextinguible, explican que para Hobbes difícilmente pueda hablarse de un Bien verdadero o supremo - pues nada en este mundo es otra cosa que un bien relativo a nuestros deseos actuales, que una vez satisfechos darán paso a otros deseos-y que los seres humanos, por naturaleza, sólo puedan verse como medios u obstáculos para sus propios intereses. En todo caso se podrá hablar de un Mal supremo o verdadero, esto es, de la muerte violenta, como algo en lo que todos podemos concordar, por lo que el fin último de la filosoffa será precisamente evitar la muerte violenta y prematura.

Frente a esta concepción de la vida y el conocimiento, Spinoza reivindicará una radicalmente opuesta. También él indicará que toda cosa, todo ente, tiende constitutivamente a perseverar en su ser. Pero dado que este ser no es un simple estar ahí, un simple conservarse biologico, sino una potencia dinámica, entonces perseverar querrá decir aumentar, expandir, afirmar expansivamente dicha potencia de existir. Aclaremos de inmediato entonces que potencia en el sentido spinozista no es poder de dominio, no es capacidad de someter y utilizar algo, sino energía expansiva, capacidad productiva, autoafirmación y autorrealización. ${ }^{8}$ De modo que si es cierto que bueno y malo son términos relativos a la afirmación o negación de la potencia de un modo o de una cosa -incluso de los seres humanos- ello no conduce a ningún relativismo que recuse la posibilidad de un verdadero bien, sino al examen de la potencia propia de los seres humanos. En este sentido el Bien supremo no es, naturalmente, algo externo, una vida más allá de esta vida, pero sí la máxima afirmación/expansión de su potencia de actuar y de entender. La filosofía, el conocimiento racional, el entendimiento en su máxima expresión no deben verse, entonces, como medios instrumentales para adquirir riquezas, comodidades o para evitar la muerte, sino como modos de afirmar la propia existencia, de perseverar en el ser, de acceder con ello a esa felicidad que en Spinoza se identifica con la alegría de ser-afirmar nuestra potencia al máximo posible.

La diferencia entre estos dos grandes sistemas filosóficos podría expresarse, así, en dos fórmulas contrapuestas. Para Hobbes se trata de evitar la muerte violenta y prematura, lo que da cuenta de que en su filosofía sea el miedo la pasión prioritaria y, por así decirlo, fundadora de la razón y del conocimiento. Para Spinoza se trata, por el contrario, de afirmar la vida -entendida en un sentido no reductible a la existencia biológica- lo que explica que el afecto primordial de su filosofía sea el amor, y su expresión más desarrollada, el amor intelectual de Dios. Tratemos de considerar esquemáticamente cómo se expresan estas perspectivas contrapuestas en las

8 Esta tesis es de Remo Bodei, cfr. su Geometrie delle passioni, Feltrinelli, Milán, 1991. Igualmente véase $\mathrm{P}$. Wienpahl, Por un Spinoza radical, Fondo de Cultura Económica, México, 1990. 
concepciones de la naturaleza y la naturaleza humana, de la moral y de la política de ambos autores.

\section{Naturaleza y naturaleza humana}

El surgimiento de la nueva ciencia significó la ruina de las concepciones medievales y antiguas acerca de la naturaleza como un Cosmos ordenado, jerárquico y teleológicamente orientado por una Inteligencia superior y trascendente. El nuevo universo infinito descubierto por Copérnico y Galileo no sólo carecía de límites y de orden axiológico, carecía también de causas finales, y había de entenderse en cambio por las solas causas eficientes y por las leyes del movimiento de los cuerpos en el espacio. Por ello, Descartes formuló su teoría de las sustancias como una manera de, por un lado, reconocer en la extensión el dominio de estas leyes y de la necesidad material, y por otro lado, de salvaguardar en la sustancia pensante o espiritual un dominio para la libertad y la finalidad o teleologia del alma humana y, sobre todo, de Dios como sustancia espiritual creadora. Así, Descartes hablaría de tres sustancias: la extensa o material, la pensante o espiritual creada, y la espiritual increada y perfecta de Dios. Esta tripartición generaría sin embargo espinosos problemas acerca de la relación (¿causal? ¿gnoseológica? ¿milagrosa?) entre ellas, con los que Descartes lucharía infructuosamente a lo largo de todas sus obras.

Tanto Hobbes como Spinoza tomarían distancia de dicha teoría de las tres sustancias. El filósofo inglés en sus objeciones a las Meditaciones metafísicas cartesianas argumentaría que de la premisa "yo pienso" no se sigue que "soy una cosa (o sustancia) pensante", sino mạ́s bien que "soy una cosa (un cuerpo) que (como una propiedad suya) piensa", de la misma manera que de la premisa "yo camino" no se sigue que "soy una cosa caminante", sino más bien que "soy una cosa (un cuerpo) que (tiene la propiedad de que) camina". Caminar o pensar no son pues, afirma Hobbes, sustancias, sino en todo caso propiedades, formas de movimiento, de determinados cuerpos. ${ }^{9} \mathrm{De}$ acuerdo con Hobbes, entonces, en la naturaleza sólo existen cuerpos y sus muy diversas formas de movimiento. Si acaso, Dios puede entenderse como la primera causa de los movimientos, pero siendo inaccesible a nuestros sentidos, se encuentra en su naturaleza más allá de nuestras capacidades cognoscitivas, y lo que de él decimos es solamente un homenaje a su poder -que suponemos supremo- y no algo epistemológicamente justificable.

Es posible entonces afirmar que Hobbes nos propone una concepción mecanicista y reduccionista de la naturaleza en tanto conjunto de cuerpos

9 De acuerdo con la versión italiana de las Meditaciones metafísicas de Descartes, Terceras Objeciones hechas por un célebre filósofo inglés, Laterza, Roma, 1992, pp. 159-185. 
en movimiento, donde nuestro saber ha de reducir en cada caso los procesos físicos a leyes de movimiento partiendo de los datos de los sentidos y, sobre todo, de definiciones precisas de las propiedades de cada cosa. Explicar los fenómenos naturales y humanos será precisamente reducirlos a diversas formas de movimiento y a sus causas eficientes, sin apelar ni a causas finales ni a presuntas causas mágicas o espirituales. El propio pensamiento humano, como veremos, deberá reducirse a efecto de los cuerpos externos sobre nuestros sentidos, así como a sus leyes peculiares.

Spinoza también rechazará la versión cartesiana de las tres sustancias, pero desde una óptica completamente diversa a la hobbesiana. Para el autor de la Ética de hecho, si tomamos en serio el concepto de sustancia -realidad que es causa sui-sólo puede hablar de una sustancia, esto es, de una realidad autosuficiente que se expresa en atributos infinitos que se desarrollan de infinitos modos. Pensamiento y extensión son por ende atributos de esa sustancia infinita y absoluta a la que también denominamos Dios o Naturaleza. De modo que Dios no es un ser o sujeto trascendente, que de la nada ha creado y ordenado a la naturaleza y a los seres humanos, sino, propiamente, esa potencia infinita de ser que se expresa singularmente en todos los modos finitos, así como en los atributos infinitos y sus leyes de movimiento y desarrollo. El cuerpo humano es así un modo de ser extenso, lo mismo que la mente humana es un modo de ser pensante, cuyo correlato es precisamente ese cuerpo.

La concepción spinozista de la Naturaleza, a diferencia de la de Hobbes, se puede denominar dinámica y pluralista, en cuanto no se trata de reducir a movimiento físico todos los fenómenos, sino de comprenderlos por sus causas próximas como expresión singular —-modificación determinadade algún atributo infinito, y por consecuencia, como afirmación de potencia o energía de existir, de ser afectado y afectar por y a otros modos. No hay necesidad de una causa primera trascendente - de un dios creador $o$ iniciador del movimiento- precisamente porque la esencia de la sustancia infinita es su potencia productiva, afirmativa, generadora de una infinidad necesaria de modos extensos y de sus ideas correlativas.

No podemos detenernos en los detalles y dificultades peculiares de estas dos visiones de la Naturaleza. Baste señalar que ambas comparten presupuestos inmanentistas y antiteleológicos, pero que difieren también en puntos esenciales relativos justamente a su relación con su sentido. Mientras que en la perspectiva hobbesiana es claro que la Naturaleza carece radicalmente de cualquier sentido, reduciéndose a un perpetuo movimiento físico de acuerdo con las leyes hipotéticas, y sólo el hombre puede construir y atribuir sentido a un mundo artificial, esto es, al mundo de la cultura que supone romper con el mundo natural, para Spinoza la Naturaleza sin duda 
no tiene un sentido trascendente - una finalidad externa en el "más allá"pero es de hecho producción infinita de un sentido inmanente infinito por cuanto es, precisamente, potencia afirmativa y productiva. Carece, pues, de significado racional, por ende, la idea de separarse de $u$ oponerse a la Naturaleza para crear una realidad supranatural o artificial: lo sepa o no, el ser humano sigue siempre y es parte finita siempre de ese orden infinito que es el mundo natural.

De estas diferencias surgen dos proyectos éticos y políticos contrapuestos: para Hobbes se trata de superar el (aparente) desorden natural, ese caos donde reinan la violencia y la guerra, fundando un orden artificial que si bien significa una renuncia a nuestro natural derecho a todo, a nuestra ilimitada libertad natural, es la condición para una vida pacífica y confortable. Para Spinoza en cambio se trata de entender al máximo a la Naturaleza y nuestra propia naturaleza, para así afirmar al máximo nuestra potencia activa limitando aquellos afectos negativos que nos entristecen y destruyen, y reconciliándonos con el único de los mundos posibles, es decir, con el mundo natural en su infinito e impersonal sentido productivo. No se trata, por ende, según esta última visión, de renunciar a quién sabe qué derecho natural o a quién sabe qué libertad natural, sino de todo lo contrario, es decir, de construir las condiciones de nuestros derechos entendidos como potencias y de nuestra libertad entendida como máxima afirmación de las mismas. $\mathrm{Ni}$ la ética es un camino de prohibiciones y renuncias, ni la política ha de pensarse exclusivamente como un método para refrenar mediante el miedo las pasiones violentas de los seres humanos. Ética es el camino de la virtud que se identifica con la felicidad, la libertad y el amor intelectual de Dios (o sea la Naturaleza). Política, al menos política razonable, es la construcción difícil pero no imposible de un orden institucional en el que predominen los afectos de alegría sobre los de tristeza, y por ende las libertades sobre las prohibiciones así como los consensos sobre las coacciones.

Para entender lo anterior es indispensable recordar brevemente las visiones que Hobbes y Spinoza proponen acerca de la condición o naturaleza humana.

En la concepción filosófica clásica de los griegos y latinos, el ser humano - como el resto de los entes - tiene una naturaleza teleológica donde siempre es fácil distinguir entre lo que los hombres son realmente y lo que deben llegar a ser a través de la educación y la disciplina. De ahí que la preocupación central de la ética y la política de Platón y de Aristóteles sea precisamente la enseñanza de las virtudes, esto es, de aquellas cualidades y hábitos que posibilitan la actualización de la areté o de la excelencia humana. En todo caso, la ética grecolatina es una ética en la que la ignorancia y la hybris -desmesura - son responsables del predominio de las pasiones 
bajas sobre las partes más elevadas del alma humana -el logos-, o de los apetitos desenfrenados sobre la inteligencia y la prudencia. A través de la paideia y/o de la disciplina y el hábito, el ciudadano de la polis ha de convertirse en virtuoso, en excelente, cultivando justamente las virtudes propias del ciudadano y, en el extremo, del filósofo, pasando de la vita activa a la vita contemplativa. ${ }^{10}$

En cambio, en la tradición judeocristiana el ser humano es visto como una naturaleza espiritual caída, degenerada, culpable por haber sido manchada por el pecado original, e incapaz de salvarse sino a través de la acción divina y por ende de la fe. Creado con libre arbitrio para elegir entre el bien y el mal, el hombre por arrogancia y soberbia -inducida de alguna manera por Satán- desobedece el mandato de su Creador, haciéndose acreedor a los males y sufrimientos a que lo somete su propia culpa. De ahí el surgimiento de esa moral ascética y hasta masoquista que considera el dolor y las penas como trámite indispensable para la purificación -justamente ascesis- del alma, que así se liberará de las tentaciones de la carne, esto es, de las pasiones sensuales que, por así decirlo, lo hacen esclavo del reino del mal. Será necesario un Redentor, un Mesías, para volverlo al camino del bien, que es un camino de renuncia a lo terrenal, donde la penitencia, el arrepentimiento y la fe posibilitarán la reconciliación con el Creador, pero más allá de este mundo y de esta vida. Las virtudes grecolatinas - fortaleza, valor, prudencia, sabiduría, magnanimidad y libertad- se trasmutarán en virtudes cristianas - humildad, pobreza, obediencia, arrepentimiento, caridad, esperanza y fe. San Agustín primero y Santo Tomás después, realizarán las grandes síntesis medievales de estas dos tradiciones bajo la supremacía, como es claro, de la judeocristiana.

Al romper con las cosmovisiones clásica y medieval, tanto Hobbes como Spinoza se distanciarán igualmente de estas concepciones acerca de la condición humana, pero sólo para formular dos percepciones muy diferentes de la misma. Como ya hemos apuntado, para Hobbes el hombre es un autómata movido por sus deseos o pasiones, mismos que lo conducen inexorablemente a afanarse por acumular poder para así estar en condiciones de satisfacer dichos deseos. En ello, apenas se distingue del resto de los animales, que al igual que él son movidos por su apetencias y sus miedos. Pero, por razones desconocidas, el ser humano posee el lenguaje, esto es, un conjunto de palabras que le sirven tanto como signos o marcas de sus percepciones, como medio para comunicarse con sus semejantes. $Y$ será el lenguaje lo que, por así decirlo, multiplicará extraordinariamente las capacidades y pasiones del hombre, convirtiéndolo en un ser que no sólo

${ }^{10}$ Cfr. al respecto, W. Jaeger, Aristóteles, Fondo de Cultura Económica, México, 1984, pp. 467-515. Del mismo autor cfr. Paideia, Fondo de Cultura Económica, México, 1978. 
puede sino debe romper con su condición puramente natural, construyendo una realidad artificial, es decir, una sociedad civil. ${ }^{11}$

En efecto, el lenguaje tendrá la consecuencia de ampliar considerablemente la capacidad de acumular y ordenar las experiencias, y con ello, de ampliar el horizonte temporal de los seres humanos. Éstos no sólo podrán recordar y aprender muchas más de sus experiencias sensibles, incluso remontándose bastante más allá de su propia existencia física particular; también podrán anticipar acontecimientos y experiencias por venir de una manera incomparablemente más grande que el resto de los animales, lo que sin duda les posibilitará un mayor dominio sobre la naturaleza, pero, al mismo tiempo, una consciencia fatal de su propia mortalidad. Todos los seres vivos son mortales, pero sólo el hombre vive desde muy pequeño en la consciencia de su propia e inevitable muerte. De ello derivará la extraordinaria fuerza de las pasiones humanas, de los miedos y de las esperanzas, de los deseos y apetitos, de su ansiedad acerca del futuro y de su tristeza o nostalgia por el pasado. De ello derivará, además, que esa incrementada capacidad cognoscitiva sea el correlato de su capacidad para caer y vivir en el error, para dejarse llevar por su imaginación y por sus sueños de grandeza, y para perder estúpidamente su vida por causa de su vanidad.

Fuente de su eminencia sobre los demás animales, el lenguaje también está en el origen de todas sus desventuras políticas, morales y religiosas. Pues, como ya había señalado Platón, si todos los hombres quieren el bien, lo bueno para ellos, ¿por qué es que no sólo hacen el mal a los demás sino a sí mismos? ¿Por qué se dejan llevar por supersticiones, imaginaciones, ensoñaciones y absurdos que sólo los pueden conducir al sufrimiento y a la muerte violenta y prematura? Respecto a esto, la postura hobbesiana parece acercarse a la propia de la tradición grecolatina, y sobre todo platónica: el origen de todo esto está en la ignorancia y en la vanidad provocada por y aliada de dicha ignorancia. Ignorancia acerca de lo que es la naturaleza humana, sus pasiones y deseos, y sus posibilidades; vanidad y arrogancia acerca de la capacidad y supuesta superioridad de unos sobre otros; vanidad y arrogancia acerca del pretendido bien supremo y la salvación, que los llevan a sacrificar su existencia por mor de ídolos y fantasmas manipulados por clérigos y teólogos ambiciosos y calculadores; arrogancia y soberbia sobre supuestas virtudes heroicas y cívicas, acaso buenas para las viejas polis de la antigüedad, pero absolutamente absurdas en el mundo actual. ${ }^{12}$

11 Sobre el papel y la teoría del lenguaje de Hobbes véase T. Magri, Saggio su Thomas Hobbes, capítulo I, Il Saggiatore, Milán, 1989.

12 Cfr. la clásica interpretación de L. Strauss, The Political Philosophy of Hobbes, Midway Reprint, Chicago, 1984. 
Ciertamente, el mero conocimiento racional —el mero cálculo exacto de nuestras pasiones y sus consecuencias- sería totalmente impotente si se opusiera siempre y necesariamente a todas nuestras pasiones. Si la demostración sobre las propiedades geométricas del triángulo afectara intereses humanos, gustaba de decir Hobbes, seguramente ella no gozaría del consenso que tiene entre los sabios. Por ello, el saber político filosófico, además de ser estrictamente racional, ha de articularse y sustentarse en alguna pasión humana, capaz a su vez de convertir dicho saber en poder efectivo. Ahora bien, dado que, como hemos señalado más arriba, Hobbes desecha la posibilidad de hallar un Bien verdadero -en la medida en que los hombres varían mucho en lo que respecta a lo que les parece bueno- sólo resta la posibilidad de descubrir un Verdadero y Supremo Mal en el que todos podamos ponernos de acuerdo, y al que, por ende, todos temamos por igual y sin excepción. En este sentido, la inferencia es fácil bajo las premisas hobbesianas: este Mal sólo puede ser no la muerte natural - temible pero inevitable - sino la muerte violenta y prematura.

En efecto, siendo la tendencia básica de los seres humanos - su conatus o deseo constitutivo- conservarse vivos, al extremo de que todos los demás apetitos y pasiones pueden reducirse a medios de esta tendencia, su derecho natural, dirá Hobbes, consiste en la libertad de usar todo tipo de recursos para continuar vivos, para hacer todo aquello que consideren conveniente para ello, con la única limitación - pues ello no sería racional- de acciones o decisiones que pongan en riesgo dicha existencia vital:

El derecho de naturaleza, lo que los escritores llaman comúnmente jus naturale, es la libertad que cada hombre tiene de usar su propio poder como quiera, para la conservación de su propia naturaleza, es decir, de su propia vida; y, por consiguiente, para hacer todo aquello que su propio juicio y razón consideren como los medios más aptos para lograr ese fin. ${ }^{13}$

Por naturaleza, entonces, los hombres tienen derecho a todo, es decir, una libertad prácticamente ilimitada en apariencia, lo que explica que, en ausencia de un poder coactivo que los obligue bajo amenazas y los contenga por miedo, sus propias pasiones y ambiciones los conduzcan a una situación de guerra de todos contra todos. Una situación, reconocerá Hobbes, tan extrema y autodestructiva que nunca ha existido por mucho tiempo, pero que tiene la ventaja de mostrar las consecuencias de la naturaleza antisocial y antipolítica de los seres humanos. Una situación, además, que permite comprender por qué es indispensable para los hombres superar la mera condición natural y convertirse en artífices de una realidad artificial, de un 
Poder soberano capaz de hacer posible la convivencia pacífica y armónica entre ellos. Sólo así se podrá pasar de un estado en que el hombre es inevitablemente el lobo del hombre, a un estado donde el hombre pueda ser un dios para el hombre. Condición para ese tránsito será no sólo el miedo - pasión pacifista por excelencia, pero siempre sometida a vaivenes y errores-, ni sólo la razón filosófica —que puede demostrar matemáticamente la necesidad de salir del estado natural pero que carece de fuerza motivacional, sino el miedo ilustrado filosóficamente, que habrá de convertir a esos salvajes animales afanosos de poder y de gloria, en civilizados súbditos de un Poder absoluto e ilimitado, posibilitando una vida segura y confortable para los mismos.

Muy otra es la posición de Spinoza relativa a la condición y a la naturaleza humanas. No porque, como Rousseau, pretenda idealizar una presunta naturaleza primitiva y silvestre de los seres humanos; no porque sus descripciones de las pasiones y afectos humanos sean menos realistas o más amables. Sino, en todo caso, porque para Spinoza, la complejidad misma del ser humano exige un tratamiento mucho más detallado y complejo de esas pasiones y afectos, y porque, sobre todo, lo que es indispensable no es tanto refrenar, embridar o castigar las pasiones, sino entenderlas y, entendiéndolas, canalizarlas y reconducirlas productiva y positivamente. Intentemos explicar este punto brevemente.

El ser humano para Spinoza no es ni la naturaleza caída de la tradición judeocristiana ni la naturaleza orientada teleológicamente hacia la virtud de los clásicos grecolatinos. No es tampoco el sujeto dotado de libre arbitrio de Descartes, cuya sola voluntad podría impedirle caer en errores teóricos y prácticos, ni por último el cuerpo pensante de Hobbes sometido a la ansiedad y al miedo por su mortalidad consciente. Es un modo de ser finito y siempre particular, dotado de un grado de potencia física e intelectual que, por supuesto, depende para su desarrollo de las circunstancias favorables y desfavorables que lo rodean. Siendo una realidad compuesta de cuerpo y mente, dicha potencia sin embargo no presupone ninguna jerarquía de lo espiritual sobre lo material ni a la inversa: se trata de la misma realidad vista a través de atributos diferentes. Más aún, la mente misma, idea del cuerpo, no es el jinete que debe someter al cuerpo-corcel, ni tampoco una estructura jerarquizada donde la inteligencia y la voluntad ocupan el lugar superior. Idea tan compleja como el propio cuerpo, nuestra consciencia no supone ningún conocimiento adecuado de nuestra mente, siendo de hecho sólo un efecto de la misma.

Modo entre otros modos, cuerpo entre otros cuerpos, mente que es solamente idea del cuerpo, el ser humano requiere de muchas cosas para existir, sobrevivir y desarrollarse adecuadamente. Su potencia mental espontánea, 
su consciencia inmediata, lejos de ser, como quería Descartes, el principio de sus certezas verdaderas, es el origen de sus representaciones imaginarias y, con ello, de sus inevitables errores y fantasías. Sin duda la imaginación expresa ya la potencia mental -ideacional- de los seres humanos, pero dicha potencia depende más del mundo que lo rodea que de la propia capacidad intelectiva. Y siendo la consciencia percepción de afectos e ignorancia de sus mecanismos productores, conduce inevitablemente a una concepción ingenuamente antropocéntrica del universo, donde todo se explica, como las propias acciones humanas, por sus fines. Encontrando muchas cosas que les son útiles, los hombres, en efecto, caen en la creencia de que el mundo mismo es una creación intencional y que las cosas fueron fabricadas para nuestro beneficio, generándose así la ilusión teológica: debe existir algún o algunos creadores que intencionalmente hicieron el mundo para algo. $Y$ descubriendo otras cosas perjudiciales, se adjudicará a los dioses creadores una voluntad de premiar y castigar las acciones humanas, exigiendo honores y ordenando mandatos más o menos absurdos. La visión antropocéntrica y teleológica se trastrocará así en ilusión teocéntrica y monárquica: ilusión que ante la presunta injusticia e irracionalidad del mundo llevará a concebir un deus absconditus, una divinidad incomprensible, cuyos designios son inescrutables. Dios se convertirá así en el asilo de la ignorancia humana, o mejor dicho, en el asilo del desconocimiento de dicha ignorancia. ${ }^{14}$

De esta visión supersticiosa e ignorante sólo nos pueden sacar la razón y el entendimiento de las causas próximas de los fenómenos, y el desarrollo por ende de nuestra capacidad intelectual. Pero dicha capacidad nunca es meramente intelectual o intelectualista en el sentido abstracto del término: es también y esencialmente una capacidad afectiva, un modo de ser afectado por y poder afectar al mundo que nos rodea. Pues en efecto, nuestra mente, en tanto idea del cuerpo, es consciente de las afecciones corporales y consciente de las ideas - confusas y mutiladas- de dichas afecciones. $O$ dicho de otra manera, nuestra pensamiento es siempre emocional, afectivo, cargado de sentimientos negativos o positivos. Para Spinoza entonces las pasiones no son afectos negativos derivados de la baja realidad de nuestro cuerpo material, son simplemente afectos, afecciones, que derivan de causas exteriores que nos superan en potencia. Por ello dichas pasiones son pasivas, porque expresan justamente nuestra dependencia y nuestra impotencia, y porque por ello mismo modulan nuestro conatus, nuestro deseo constitutivo de perseverar/afirmar nuestro ser.

14 Cfr. el apéndice de la primera parte de la Ética, Alianza editorial, Madrid, 1986, pp. 89-98. Cfr. igualmente de A. Matheron, Individu et communauté chez Spinoza, ed. Minuit, 1988, segunda parte. 
Sin embargo, estos afectos pasiones son de dos tipos: unos, los de alegría, suponen un aumento de nuestra potencia; otros, los de tristeza, disminuyen nuestra capacidad de actuar y de entender. El amor y el odio, la esperanza y el miedo, así como el innumerable resto de nuestras pasiones, son derivaciones y composiciones de estos afectos básicos que justamente forman y transforman ese deseo de perseverar y de afirmar nuestra existencia. Pero en todo caso, lo que importa es que, por consecuencia, las pasiones y los afectos son todos fenómenos naturales que se explican y entienden por sus causas próximas, y no quién sabe qué perversiones o desviaciones contra natura. No se trata, por ende, de verlas como algo que simplemente haya que reprimir, refrenar o incluso exterminar, sino como energía afectiva que inexorablemente ha de expresarse de un modo o de otro.

Contra toda moral ascética, Spinoza propondrá entonces algo muy diferente al miedo acorazado de coërción y racionalmente justificado de Hobbes: una terapia intelectual/afectiva sustentada en el predominio de los afectos-pasiones alegres sobre los afectos-pasiones tristes. Una terapia expansiva que logre identificar entendimiento con transmutación de las pasiones en energía afectiva positiva que tienda a incrementar al máximo nuestras capacidades corporales y mentales, reconciliándonos con la naturaleza, con nuestros semejantes y con nosotros mismos, al permitimos alcanzar la felicidad eterna implicada en el amor intelectual de Dios. Para ello será indispensable un difícil esfuerzo de rigor intelectual, de crítica de nuestros prejuicios, de disciplinamiento mental y corporal, pero no en nombre de una renuncia ascética, sino de una alegría y de un contento plenamente racionales, afirmativos, constructivos. Es, si se quiere, una ética sólo para los sabios, para los que pueden encontrar en la razón y en el entendimiento una alegría que a muchos parecerá extraña y hasta extravagante, pero que quizá pueda compararse con la felicidad del virtuoso artístico, del pianista o del pintor capaces de disfrutar tanto sus actividades porque justamente así se realizan plenamente.

No puede sorprender por lo anterior que la propuesta política spinozista tenga que ser totalmente opuesta a la de Hobbes. Definiendo rigurosamente el derecho natural de los seres humanos - como el derecho natural de cualquier cosa- por su potencia individual, Spinoza en todo caso identificará la hipótesis de un estado de naturaleza no con un estado de guerra de todos contra todos, sino con una situación de impotencia y aislamiento generalizados, donde el presunto derecho a todo sería equivalente, por ello mismo, a un derecho a nada. ${ }^{15}$ Mostrando además que el miedo es, por esencia, una pasión triste y negativa, y que por ello sólo puede promover la ignorancia,

15 Cfr. B. Spinoza, Tratado polltico, Alianza editorial, Madrid, 1986, capitulo II, §15, p. 92. 
la superstición y el fanatismo, el autor del Tratado teológico-político llegará a la conclusión de que las tiranías y los despotismos sólo pueden conducir a la debilidad, a la violencia y a la esclavitud humanas. Sólo la esperanza razonable y las instituciones capaces de canalizarla y extenderla, podrán ser una base firme para un Estado y una sociedad que no conciban la paz como simple pasividad y pervivencia biológica, sino como posibilidad de desarrollar capacidades humanas de todo tipo. Sólo la democracia o sistemas que amplíen al máximo la participación y las capacidades y pasiones alegres de los seres humanos, podrán, de acuerdo con esta impresionante reflexión filosófica, posibilitar que se enfrenten los desafíos de la modernidad desde una ética y una política propiamente racionales y propiamente modemas.

Tenemos, pues, dos visiones filosóficas paradojicamente emparentadas pero inconmensurables de la modernidad. Dos perspectivas éticas y politicas de lo humanamente posible y deseable. Cuál ha sido, y por qué, la históricamente dominante es una interrogante que excede con mucho los límites del presente ensayo, pero que debiera llevar a reflexionar desde nuestro crítico presente. En todo caso, invitar a la lectura cuidadosa de Hobbes y Spinoza ha sido la intención de las líneas anteriores. 